\title{
Pseudomyxoma peritonei in a pediatric patient: A case report and literature review
}

\author{
Ana Claudia de Oliveira Fernandes ${ }^{1}$, Gustavo Ricardo Martins da Rocha ${ }^{1}$, Alex Dias de Oliveira ${ }^{1 *}$ (0, \\ Marcos Duarte Guimarães ${ }^{1}$, Stefane Cajango de Carvalho $^{1}$, Rubens Chojniak ${ }^{1}$ \\ ${ }^{1}$ Department of Radiology and Imaging Diagnosis, Hospital A.C. Camargo Cancer Center, São Paulo, SP, Brazil
}

Study conducted at A.C. Camargo Cancer Center, São Paulo, SP, Brazil

Article received: $5 / 10 / 2017$ Accepted for publication: 6/26/2017

*Correspondence: Address: Rua Professor Antônio Prudente, 211 São Paulo, SP - Brasil Postal code: 04111-000 imeiodoalex@ig.com.br

\section{SUMMARY}

Introduction: Pseudomyxoma peritonei (PMP) is a rare clinical condition, with an incidence of 1-2 cases per million, characterized by the dissemination of mucinous implants on the peritoneal surface and progressive gelatinous ascites. Although it usually presents an indolent behavior, its non-specific clinical presentation contributes to many cases remaining undiagnosed until a laparotomy is performed. With late diagnosis, performed after a long period of clinical deterioration and disease progression, it is common to find complications such as the formation of intestinal fistulas and obstruction.

Method: Review of the medical record and search for references in the Medline, Lilacs, SciELO and MD Consult databases.

Results: There are rare case reports found in the literature demonstrating atypical PMP presentations. Our report is that of a 17-year-old adolescent with a sporadic tumor diagnosed in a primary site in the transverse colon, contrary to data commonly found in the literature that mention a more frequent occurrence in women in the fifth decade of life and with a primary site in the ovary and appendix. The development of mucinous adenocarcinoma is rare in the pediatric population, and topography in the transverse colon and non-familial sporadic pattern are unusual.

Conclusion: The case reported not only raises awareness about the atypical presentations of the disease, but also emphasizes the use of imaging examinations for diagnosis, which has an important impact on prognosis and survival if performed timely.

Keywords: Pseudomyxoma Peritonei. Child. Tomography, X-ray Computed. Magnetic Resonance Spectroscopy.

\section{INTRODUCTION}

Pseudomyxoma peritonei (PMP) is a rare clinical condition, with an incidence of $1-2$ cases per million, and more frequent in women over 50 years (peak incidence at age 52 ). It is characterized by the dissemination of mucinous tumor implants on the peritoneal surface and the progressive development of gelatinous ascites throughout the abdominopelvic cavity, resulting in the so-called jelly belly. ${ }^{1-4}$

PMP has different forms of presentation and is classified into three subtypes: disseminated peritoneal adenomucinosis (DPAM), which includes histopathologically benign peritoneal lesions; peritoneal mucinous carcino- matosis (PMCA), which includes malignant lesions of a more aggressive course; and a third borderline subtype called peritoneal mucinous carcinomatosis, which exhibits intermediate features. ${ }^{5-7}$

It has an indolent behavior, with nonspecific clinical manifestations resulting from the compression of intraabdominal structures, such as distension and pain, mechanical or functional intestinal obstruction, intestinal habit changes, nutritional failure and malnutrition secondary to increased pressure, fistulae, and infection. ${ }^{1,2,8}$

Although ovary and appendix are implicated as the most common primary sites, PMP may also originate 
from other sites such as the ovarian tubes, pancreas, spleen and small intestine, while in some cases the primary site remains unknown. ${ }^{1,2}$

Imaging findings make an important contribution to the diagnostic elucidation, with computed tomography being the most used modality. Its main findings include ascites with low attenuation coefficient and the presence of heterogeneous mass with soft tissue density, which may or may not reveal gross calcifications or septations. ${ }^{1,9}$

To date, few cases of PMP in young patients with primary site located in the colon have been described in the literature. For this reason, we report this case of PMP in a 17-year-old pediatric patient evaluated using whole body CT and MRI.

\section{Method}

We performed the analysis of the medical record plus a bibliographic search in the Medline, Lilacs, SciELO and MD Consult databases.

\section{Results}

\section{Clinical findings}

A 17-year-old male patient, mixed race, medical student from the state of Amazonas, referred to the pediatric oncology department of this hospital complaining of four months of colic-type pain in the hypogastrium associated with dysuria and fever. The clinical picture progressed with weight loss, gastric fullness, postprandial vomiting and increased abdominal volume. On admission, the patient had a flat abdomen with a palpable abdominal mass of hardened consistency extending from the pelvis to the epigastric region, measuring approximately $20 \mathrm{~cm}$.

$\mathrm{He}$ did not present previous comorbidities or family history of neoplasia. He denied having a habit of smoking or alcohol abuse. Laboratory results on hospital admission revealed left shift leukocytosis, platelet count at 768,000, CEA at 14.5 (RV up to 9.0) and CA 19.9 at 114.8. We observed a progressive increase in the levels of CEA and CA 19.9 over time.

\section{Imaging findings}

The patient brought an abdominal ultrasound from another service, which showed hypoechoic images with solid consistency, measuring about $8 \mathrm{~cm}$ in the epigastrium and mesogastrium, and also in the left iliac fossa, measuring $5 \mathrm{~cm}$.

He underwent a CT scan of the abdomen and pelvis that revealed expansive lesions presenting soft tissue density, sometimes with foci of diffuse calcifications distributed in the abdominopelvic cavity, involving and displacing structures such as small intestine and colon loops towards the left flank, as well as surrounding the structures of the hepatic hilum, and causing scalloping of the liver capsule (Figure 1).

Whole-body magnetic resonance imaging was also performed, as it is a method that allows the visualization of the entire body with high resolution. The method has been gaining relevance in the evaluation of pediatric patients, since it does not use ionizing radiation, which has the potential to cause damage to the DNA with consequent increase in the risk of cancer. MRI showed multiple disseminated confluent lesions in the peritoneal cavity, with lobulated contour, exerting a compressive effect on the abdominal structures, especially on the hepatic surface, where the contours of the organ appeared scalloped, as well as compression and displacement of intestinal loops. These lesions showed low signal intensity on T1, and high intensity on Stir and diffusion weighted sequence (Figure 2).

\section{Anatomopathological findings}

A mass biopsy of the peritoneal cavity was performed, resulting in a histological study compatible with mesenchymal neoplasia, showing giant and signet ring cells. Immunohistochemical analysis compatible with high-grade mucoprodutant colon adenocarcinoma with loss of protein expression of the repair genes MLH1 and PMS2 (Figure 3).

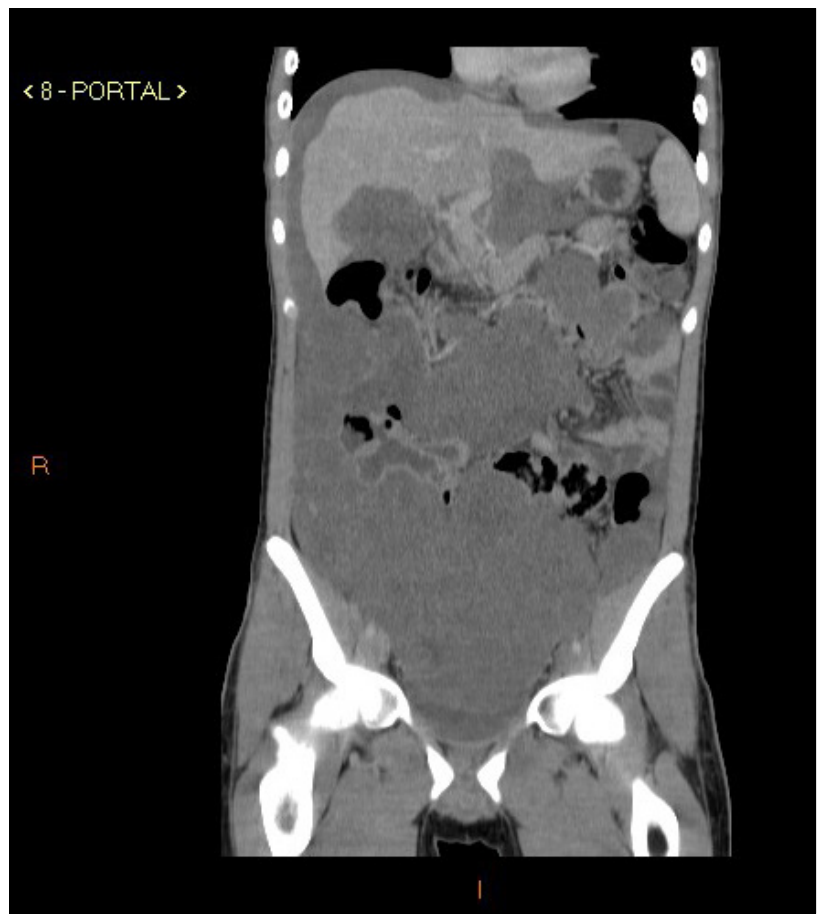

FIGURE 1 Multiple hypodense lesions throughout the peritoneal cavity, displacing intestinal loops and scalloping of the liver capsule. 


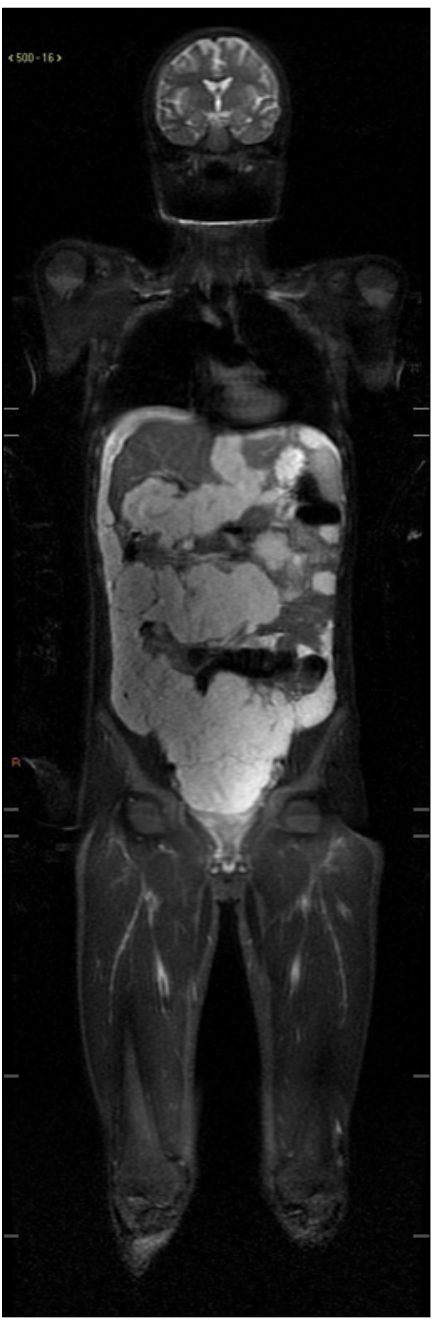

FIGURE 2 Coronal stir sequence demonstrating multiple disseminated peritoneal lesions with high intensity signal. No lesions were found elsewhere in this study.

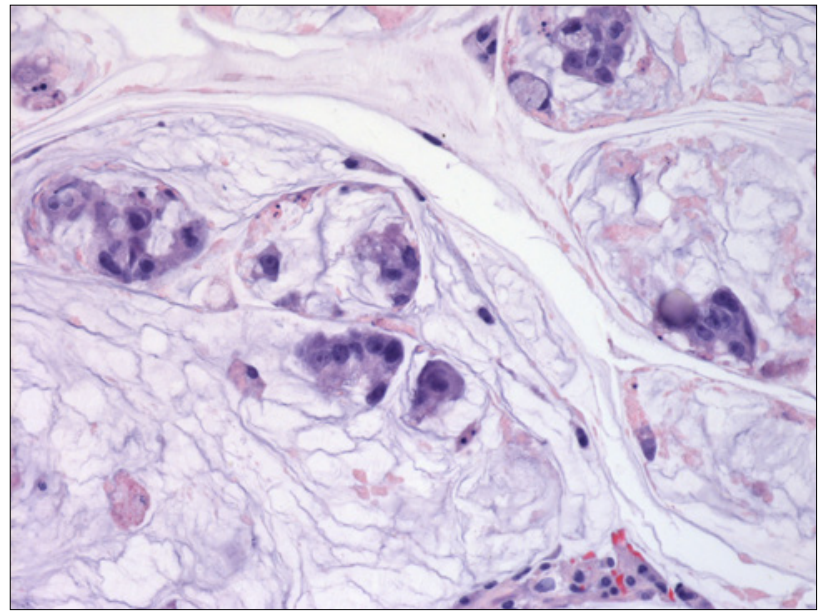

FIGURE 3 Slide demonstrating neoplasm with mesenchymal appearance, exhibiting giant and signet ring cells.

\section{Treatment}

The patient underwent surgery under general anesthesia with a xipho-pubic incision allowing extensive investigation of the entire cavity. We were able to visualize: ascites mucinous, voluminous mass in the mesogastrium involving the omentum, right and transverse colon, sparing the appendix, transverse mesocolon and mesenteric root, multiple peritoneal and pelvic implants and masses in the supra-mesocolic area involving the splenic and hepatic hila and the small gastric curvature. There was no evidence of involvement of the hepatic parenchyma and large vessels. We considered performing cytoreduction in two steps, with the infra-mesocolic approach performed first due to its greater extension and symptoms. Enterectomy, extended right hemicolectomy with colostomy at the level of the splenic flexure, anastomosis of the descending ileum, and resection of abdominal and pelvic mass were performed.

\section{Follow-up}

Patient presented disease progression, with inadequate response to oxyplatin chemotherapy. He underwent surgery for cytoreduction in the supra-mesocolic area, and a large amount of mucin was found in the abdominopelvic cavity, with diffuse infiltrative pattern carcinomatosis involving the mesenteric root, hepatic hilum and pelvis, with the disease progressing aggressively in the previously operated area. Due to the criteria of irresectability and intolerance to chemotherapy, the patient was treated with palliative care, evolving with septic shock and death about 15 months after the onset of symptoms.

\section{Discussion}

PMP is an uncommon clinical condition, with an incidence of 1 for every 5,000 laparotomies, characterized by the presence of ascites and diffuse mucinous neoplastic cells in the abdominal cavity. It is most evident in women after the fifth decade of life, with the ovary being the most frequent primary site, with a predominance of the cecal appendix in men. ${ }^{2,3,5,6,10-12}$ The reported case refers to a male adolescent, aged 17 years at diagnosis, the primary site being the transverse colon, with histology compatible with sporadic mucinous adenocarcinoma, as opposed to reports commonly found in the literature. $2,3,5,6,10,11$

Although it usually presents an indolent behavior, its non-specific clinical presentation contributes to many cases remaining undiagnosed until a laparotomy is performed. With late diagnosis, performed after a long period of clinical deterioration and disease progression, it is common to find complications such as the formation 
of intestinal fistulas and obstruction, consequent to the occupation of the whole cavity by mucinous masses. ${ }^{5,11,13}$

Imaging tests play an important role in diagnostic elucidation and therapeutic planning. Computed tomography $(\mathrm{CT})$ is considered the imaging modality of choice, with findings that may be considered pathognomonic. Characteristic findings include the presence of amorphous areas of low attenuation with foci of hyperattenuation, which represent solid material with mucin, which may or may not be associated with foci of gross calcification or septation. Scalloping of the visceral surfaces, especially the spleen and liver, may also contribute by differentiating the mucinous ascites from other forms of ascites. The pattern of disease distribution initially at sites of limited peristalsis, progressing to occupy the entire abdominal cavity, also helps in the investigation. ${ }^{1,5-7,11,14,15}$

Contrast-enhanced tomography may provide information such as signs of obstruction in small bowel loops and intra-abdominal masses greater than $5 \mathrm{~cm}$, indicating the risk of incomplete cytoreduction, which is critical for surgical programming. ${ }^{11,16}$

Although it is an innocuous and widely available imaging modality, ultrasonography cannot be used alone because mucinous ascites can resemble free intraperitoneal fluid. It can be used, however, to guide fine needle biopsies, providing a cytological diagnosis. ${ }^{5}$

Although the role of nuclear magnetic resonance still remains unclear, this method has shown promise for staging and treatment planning. In the case reported, classic findings guided the diagnosis of pseudomyxoma peritonei. Whole-body MRI also demonstrated masses with mucous appearance exerting compressive effect on the structures of the abdominal cavity scalloping of liver and spleen. There were no signs of distant metastases. ${ }^{7,10,11,15}$

Clinical evaluation of our patient with PMP included the investigation of tumor biomarkers, namely CEA and CA 19-9, generally found at high levels in situations such as this. These biomarkers are related to prognosis and, if levels are high, they are associated with a higher risk of relapse and lower overall survival, despite aggressive therapy. ${ }^{10,17-19}$

There is still no consensus on the best PMP treatment; the strategies vary widely, according to the clinical picture and extent of the disease. Cytoreductive surgery, which consists of the macroscopic removal of tumor masses, combined with intraperitoneal and systemic postoperative hyperthermic chemotherapy, are the strategy of choice for attempted cure. Patients eligible for the procedure cannot be older than 75 years, have severe or decompensated comorbidities and extensive disease affecting the mesentery and small intestine (with more than one point of stenosis), the hepatic hilum, pancreas, abdominal wall, retroperitoneum and extraperitoneal structures.

If the patient is unable to undergo the procedure, palliative resection of part of the disease can be performed to guarantee relief of symptoms. In some cases, palliative clinical treatment may also be performed with symptom control and clinical follow-up through physical examination and investigation of laboratory markers depending on the patient's conditions. ${ }^{2,9,16,20,21}$

\section{Conclusion}

Due to the rare occurrence and presence of nonspecific clinical manifestations, PMP remains a diagnostic challenge for both physicians and radiologists. It is important to recognize their forms of atypical presentation, which may include young patients with unusual primary sites such as spleen, pancreas, colon, urachus, and other organs. It is also essential that radiologists are aware of the specific imaging aspects, providing early diagnosis with a consequent impact on disease prognosis.

\section{Resumo}

Pseudomixoma peritoneal em paciente pediátrico: relato de caso e revisão de literatura

Introdução: O pseudomixoma peritoneal (PMP) é uma condição clinica rara, com incidência de 1-2 casos por milhão, caracterizada pela disseminação de implantes de natureza mucinosa pela superfície peritoneal e acúmulo progressivo de ascite gelatinosa. Embora apresente geralmente um comportamento indolente, a apresentação clínica inespecífica contribui para que muitos casos permaneçam sem diagnóstico até a realização de laparotomia. Com o diagnóstico tardio, realizado após um longo período de deterioração clínica e progressão de doença, é comum encontrar complicações, como a formação de fístulas e obstruções intestinais.

Método: Revisão do prontuário médico e pesquisa bibliográfica nas bases de dados Medline, Lilacs, SciELO e MD Consult.

Resultados: São raros os relatos de caso encontrados na literatura que demonstram apresentações atípicas do PMP. O presente estudo apresenta o caso de um adolescente com 17 anos ao diagnóstico e sítio primário no colón transverso com tumor esporádico, contrário aos dados comumente encontrados na literatura, que referem acometimento mais comum em mulheres na quinta década 
de vida e com sítio primário em ovário e apêndice. O desenvolvimento de adenocarcinoma mucinoso é raro na população pediátrica e a topografia no cólon transverso e padrão esporádico não familial também são pouco usuais. Conclusão: $O$ caso relatado alerta para as apresentações atípicas da doença e enfatiza o uso de exames de imagem para o diagnóstico, que, se realizado precocemente, impacta de maneira importante o prognóstico e a sobrevida.

Keywords: Pseudomixoma Peritoneal. Criança. Tomografia Computadorizada por Raios X. Espectroscopia de Ressonância Magnética.

\section{References}

1. Chauhan A, Patodi N, Ahmed M. A rare cause of ascites: pseudomyxoma peritonei and a review of the literature. Clin Case Rep. 2015; 3(3):156-9.

2. Pandey A, Mishra AK. Pseudomyxoma peritonei: disseminated peritoneal adenomucinosis variant. BMJ Cases Rep. 2011; 2011.

3. Guo AT, Li YM, Wei LX. Pseudomyxoma peritonei of 92 Chinese patients: clinical characteristics, pathological classification and prognostic factors. Word J Gastroenterol. 2012; 18(24):3081-8.

4. Mavrodin CJ, Pariza G, Iordache P, Iorga P, Sajin M. Pseudomyxoma peritonei: a rare entity difficult to diagnose and treat - case report. Chirurgia (Bucur). 2014; 109(6):846-9.

5. Amini A, Masoumi-Moghaddam S, Ehteda A, Morris DL. Secreted mucins in pseudomyxoma peritonei: pathophysiological significance and potential therapeutic prospects. Orphanet J Rare Dis. 2014; 9:71.

6. Spyropoulos C, Rentis A, Alexaki E, Triantafillidis JK, Vagianos C. Appendiceal mucocele and pseudomyxoma peritonei, boundaries of a subtle disease. Am J Case Rep. 2014; 15:355-60.

7. Lee NK, Kim S, Kim HS, Jeon TY, Kim GH, Kim DU, et al. Spectrum of mucin-producing neoplastic conditions of the abdomen and pelvis: cross-sectional imaging evaluation. World J Gastroenterol. 2011; 17(43):4757-71.
8. Lemahieu J, D’Hoore A, Deloose S, Sciot R, Moerman P. Pseudomyxoma peritonei originating from an intestinal duplication. Case Rep Pathol. 2013; 2013:608016.

9. Tirumani SH, Fraser-Hill M, Auer R, Shabana W, Walsh C, Lee F, et al Mucinous neoplasms of the appendix: a current comprehensive clinicopathologic and imaging review. Cancer Imaging. 2013; 13:14-25.

10. Sugiyama K, Ito N. Mucinous cystadenocarcinoma of the urachus associated with pseudomyxoma peritonei with emphasis on MR findings. Magn Reson Med Sci. 2009; 8(2):85-9.

11. Bevan KE, Mohamed F, Moran BJ. Pseudomyxoma peritonei. World J Gastroinst Oncol. 2010; 2(1):44-50.

12. Nikolic O, Djurdjevic S, Stojanovic S, Basta Nikolic M, Mocko Kacanski M, Secen S. Pseudomyxoma peritonei: case report. Eur J Gynaecol Oncol. 2012; 33(2):227-9.

13. Joo MW, Chung YG, Hur SY, Lee A, Jung CK, Jee WH, et al. Pseudomyxoma peritonei extending to the lower extremity: a case report. World J Surg Oncol. $2015 ; 13: 221$.

14. Dixit A, Robertson JH, Mudan SS, Akle C. Appendiceal mucocoeles and pseudomyxoma peritonei. World J Gastroenterol. 2007; 13(16):2381-4.

15. Levy AD, Shaw JC, Sobin LH. Secondary tumors and tumorlike lesions of the peritoneal cavity: imaging features with pathologic correlation. Radiographics. 2009; 29(2):347-73.

16. Fallis SA, Moran BJ. Management of pseudomyxoma peritonei. J Buon. 2015; 20(Suppl 1):S47-55

17. Touloumis Z, Galyfos G, Kavouras N, Menis M, Lavant L. Aggressive pseudomyxoma peritonei: a case report with an unusual clinical presentation. Case Rep Oncol Med. 2013; 2013:926963.

18. Li C, Kanthan R, Kanthan SC. Pseudomyxoma peritonei: a revisit - report of 2 cases and literature review. World J Surg Oncol. 2006; 4:60.

19. Di Fabio F, Aston W, Mohamed F, Chandrakumaran K, Cecil T, Moran B. Elevated tumour markers are normalized in most patients with pseudomyxoma peritonei 7 days after complete tumour removal. Colorectal Dis. 2015; 17(8):698-703.

20. Funder JA, Jepsen KV, Stribolt K, Iversen LH. Palliative surgery for pseudomyxoma peritonei. Scand J Surg. 2016; 105(2):84-9.

21. Loungnarath R, Causeret S, Bossard N, Faheez M, Sayag-Beaujard AC, Brigand $\mathrm{C}$, et al. Cytoreductive surgery with intraperitoneal chemohyperthermia for the treatment of pseudomyxoma peritonei: a prospective study. Dis Colon Rectum. 2005; 48(7):1372-9. 